Dr Neil Smith, FRCP, is consultant dermatologist and honorary senior lecturer in histopathology at the Institute of Dermatology, St John's Hospital for Diseases of the Skin, London WC2H 7BJ, and Dr Margaret Spittle, MSC, FRCR, is consultant radiotherapist and oncologist at St John's Hospital for Diseases of the Skin and the Middlesex Hospital, London W1N 8AA.

The photograph of lymphoma was reproduced by kind permission of DrCharles Farthing. lymphoma is difficult. The use of intravenous multiple agent chemotherapy regimens (CHOP or MBACOP) has resulted in complete initial remission, but there is a high relapse rate with poor response to second line chemotherapy. The commonly found disease of the central nervous system dictates that CNS irradiation or intrathecal chemotherapy should be given. Although some long term responses have been noted, median survival of these patients is poor and is usually less than a year. Most patients die from their lymphoma, although others succumb to opportunistic infections. Patients are treated aggressively with cytotoxic regimens if the symptoms of lymphoma appear before the opportunistic infections of AIDS, but if the patient has had recurrent infective episodes radical chemotherapy treatment is often curtailed or withheld. The rare cases of low grade lymphoma should be treated conservatively.

\title{
Rubella susceptibility and the continuing risk of infection in pregnancy
}

\author{
CHRISTINE L MILLER, ELIZABETH MILLER, PAULINE A WAIGHT
}

In November 1983 the Department of Health and Social Security launched a campaign to increase, over three years, the uptake of rubella vaccination in schoolgirls and women. As part of this initiative the Public Health Laboratory Service, with funding from the Office of the Chief Scientist, set up a study to monitor rubella susceptibility and infection in pregnancy and to determine vaccine uptake in non-immune women. The study began in 1984 in eight public health laboratories (Ashford, Bristol, Gloucester, Hereford, Leeds, Luton, Manchester, and Reading) which together screen over 100000 pregnant women each year, about one sixth of the annual antenatal population of England and Wales.

\section{Methods}

In the eight laboratories the request form for antenatal rubella screening was changed to include a question on parity, a microcomputer was installed for entry of all rubella data, and a nurse was appointed to inquire into the vaccination of non-immune women. Data, including the results of diagnostic screening, were analysed at the Communicable Disease Surveillance Centre of the Public Health Laboratory Service from discs sent from each laboratory. Each case of rubella infection in pregnancy reported to the Communicable Disease Surveillance Centre from laboratories in England and Wales was followed up through the microbiologist, obstetrician, and general practitioner.

PHLS Communicable Disease Surveillance Centre, London NW9 5HT CHRISTINE L MILLER, MFCM, senior epidemiologist ELIZABETH MILLER, MB, BS, principal microbiologist PAULINE A WAIGHT, BSC, computer analyst

Requests for reprints and correspondence to: $\operatorname{Dr} C L$ Miller.

\section{Results}

ANTENATAL SUSCEPTIBILITY

The results for Manchester showed that in the annual antenatal population of around 40000 the proportion susceptible to rubella fell from $6.7 \%$ in 1979 to $2 \cdot 7 \%$ in 1984 ; susceptibility was lower in parous than in nulliparous women. ${ }^{\prime}$ Continued surveillance of this antenatal population has shown no further decline in susceptibility over the two and a half years since April 1984 (fig 1).

Results from five of the other seven study laboratories for which data were available from January 1985 showed an overall decline in susceptibility to rubella in both nulliparous and parous women over the period (table). The downward trend was significant for the five laboratories combined $(\mathbf{p}<0.05)$ but was not observed in two individual laboratories (Ashford and Reading).

\section{VACCINATION OF NON-IMMUNE WOMEN}

Initially the study nurses found that local postpartum vaccination policies and their implementation were variable. For instance, in the population served by one laboratory only four out of $81(5 \%)$ non-immune women who delivered between January 1984 and May 1985 had been vaccinated. After action by the nurse, in the first six months of 198641 out of $49(84 \%)$ non-

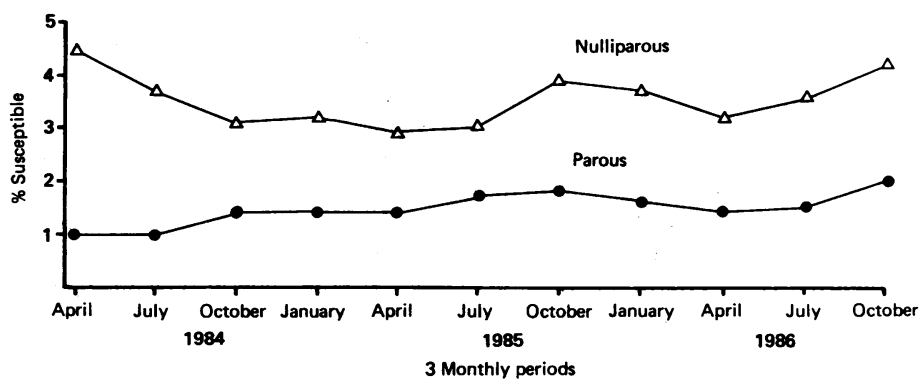

FIG 1-Susceptibility to rubella among women tested antenatally in Manchester April 1984-December 1986. 
Number of women tested antenatally and number susceptible to rubella according to parity, in five public health laboratories in two six month periods

\begin{tabular}{|c|c|c|c|c|c|c|}
\hline \multirow[b]{3}{*}{ Period } & \multicolumn{3}{|c|}{ Nulliparous } & \multicolumn{3}{|c|}{ Parous } \\
\hline & \multirow[b]{2}{*}{ Tested } & \multicolumn{2}{|c|}{ Negative } & \multirow[b]{2}{*}{ Tested } & \multicolumn{2}{|c|}{ Negative } \\
\hline & & No & $\%$ & & No & $\%$ \\
\hline $\begin{array}{l}\text { Jan-June } 1985 \\
\text { Jan-June } 1986\end{array}$ & $\begin{array}{l}11213 \\
10531\end{array}$ & $\begin{array}{l}352 \\
284\end{array}$ & $\begin{array}{l}3 \cdot 2 \\
2 \cdot 7\end{array}$ & $\begin{array}{r}10687 \\
9626\end{array}$ & $\begin{array}{l}192 \\
106\end{array}$ & $\begin{array}{l}1.8 \\
1 \cdot 1\end{array}$ \\
\hline
\end{tabular}

*Ashford, Bristol, Leeds, Luton, and Reading.

immune women were vaccinated. Overall, of the 1041 non-immune women followed up by the nurses during 1986, 907 (87\%) were vaccinated after delivery. One hundred and seventy women found to be non-immune on antenatal screening subsequently aborted; of these only $74(44 \%)$ were vaccinated, despite the nurses' efforts.

The study also showed that of 2272 non-pregnant women found on routine prevaccination screening to be susceptible, only $1431(63 \%)$ were vaccinated; an additional $204(9 \%)$ were eventually vaccinated after action by the nurses.

\section{RUBELLA INFECTIONS IN PREGNANCY 1985-6}

In 1985 the highest rate of confirmed rubella in pregnancy reported by the eight study laboratories was from Ashford, where 12 women out of the susceptible antenatal population of $403(3 \%)$ were infected. In 1986 the highest rate- $6 \cdot 7 \%$-was reported from the Luton laboratory: 10 cases among the 150 pregnant women found to be susceptible.

In 1985, 98 confirmed rubella infections in pregnancy were reported to the Communicable Disease Surveillance Centre from laboratories in England and Wales; in 1986 the total was 196 (fig 2). These figures suggest that the rubella outbreak in 1986 was larger than that in the previous year and this was confirmed by the greater number of laboratory confirmed cases in children-386 in 1986 compared with 152 in 1985.

The stage of pregnancy was ascertained for 290 of the women infected; in $173(60 \%)$ infection occurred during the first 16 weeks. Information on parity was obtained for 235 women: $103(44 \%)$ were parous, over half of whom (58) had had two or more previous births. One woman was infected in her sixth and another in her seventh pregnancy; both had been screened and reported non-immune in their previous pregnancies but had not been vaccinated.

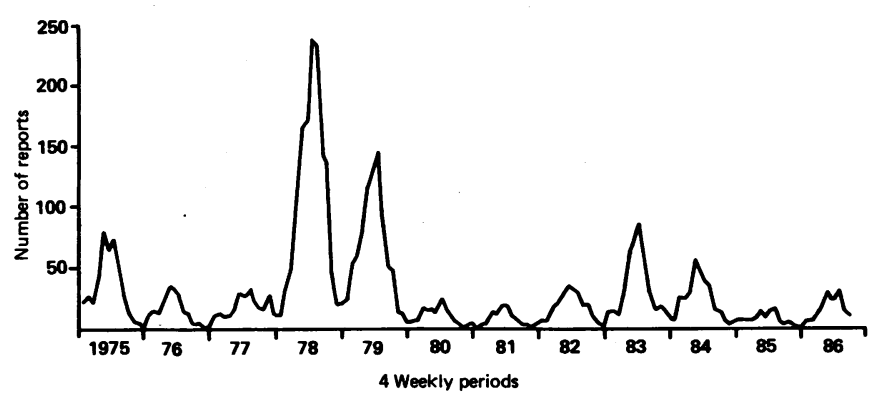

FIG 2-Pregnant women with laboratory confirmed rubella (from PHLS reports January 1975-September 1986).
Twenty four women had been reported immune on previous screening, and a further eight had a documented history of rubella vaccination. Of these $32,17(53 \%)$ had asymptomatic infections, compared with only 21 of the 230 (9\%) for whom clinical information was available and who had no history of immunity or vaccination. This difference suggests that reinfection rather than primary infection may have occurred in some of the women previously vaccinated or reported immune. In most cases, however, it was not possible to make a firm diagnosis on the available serological evidence. Of the $\mathbf{3 2}$ women reported here, 13 chose to have their pregnancies terminated, and follow up of those who continued to term identified seven congenitally infected infants (rubella specific IgM antibody in cord blood), one of whom had rubella defects. In three of these seven cases the maternal infection was asymptomatic.

\section{Discussion}

Our results confirm that susceptibility to rubella in women of childbearing age was already at or near a minimum when the national campaign was launched in $1983 .{ }^{2}$ They also confirm the Manchester experience that even with individual follow up of nonimmune women total vaccination of the target population cannot be achieved. ${ }^{1}$ The risk of infection in those who remain susceptible is directly dependent on the prevalence of rubella, particularly among children.

Thirty two women in the study who had confirmed rubella in pregnancy had previously been vaccinated or reported immune. Some may have had reinfections, which are not thought to present a risk to the fetus. ${ }^{3}$ However, the birth of seven congenitally infected infants to women in this group demonstrates that some had primary rubella. It also confirms the importance of full serological investigation of all pregnant women in contact with rubella, irrespective of a history of vaccination or immunity, or the absence of rash. Even when all the available clinical and serological evidence is obtained, however, it may still be impossible to distinguish with certainty between primary rubella and reinfection. ${ }^{4}$ Such diagnostic problems, and the continuing risk of infection in pregnancy to those who remain susceptible, are the direct result of the uncontrolled circulation of rubella in children. This study provides further evidence that to eliminate congenital rubella the current selective vaccination policy must be augmented by the additional rubella vaccination of children of both sexes.

We thank all microbiologists, obstetricians and general practitioners who provided the information.

\section{References}

1 Miller CL, Miller E, Sequeira PJL, Cradock-Watson JE, Longson M, Wiseberg EC. Effect of selective vaccination on rubella susceptibility and infection in pregnancy. $\mathrm{Br} M e d$ J 1985;291: 1398-401.

2 Miller CL, Miller E. Rubella vaccination in the UK: time for a complete strategy. Lancet 1985;ii:732.

3 Cradock-Watson JE, Ridehalgh MKS, Anderson MJ, Pattison JR. Outcome of asymptomatic infection with rubella virus during pregnancy. $\mathcal{F} H y g($ Lond) $1981 ; 87: 147-54$.

4 Morgan-Capner P, Hodgson J, Hambling MH, et al. Detection of rubella-specific IgM in Morgan-Capner $P$, Hodgson J, Hambling MH, et al. Detection
subclinical rubella reinfection in pregnancy. Lancet 1985 ;i:244-6.

\section{What is the latest thinking on the prevention and treatment of altitude sickness?}

Acute mountain sickness and its more serious forms, high altitude cerebral and pulmonary oedema, occur when unacclimatised lowlanders visit 3500 $5000 \mathrm{~m}(6733-8000 \mathrm{ft})$. There is no real substitute to gradual acclimatisation and most people will have symptoms of acute mountain sickness (headache, nausea, and malaise) if they sleep at a height of around $4000 \mathrm{~m}$ without a stay of several days at a lower altitude.' Many organisers of Himalayan treks disregard this advice with the result that several of their clients develop acute mountain sickness and a few suffer serious medical problems (or die) from high altitude oedemas. Acetazolamide has been clearly shown, when taken prophylactically, to prevent the symptoms of acute mountain sickness. ${ }^{2}$ The usual dose is acetazolamide $\mathbf{2 5 0} \mathrm{mg}$ twice daily taken for three days before travelling to high altitudes. The treatment of this self limiting condition is to rest and use simple analgesics until it passes, usually within two or three days. High altitude pulmonary oedema (recognised initially by breathlessness at rest) and high altitude cerebral oedema (recognised by ataxia of gait and severe headaches), both of which are potentially fatal, demand immediate evacuation to a lower altitude. Oxygen is useful, as is dexamethasone. Diuretics do not seem to be of value. Above all, rapid descent, even of several hundred metres, often brings about rapid recovery.-CHARLES CLARKE, consultant neurologist and honorary medical officer, British Mountaineering Council, London.

1 UIAA information sheet. Acclimatisation, acute monntain sickness and travel to high altitudes. 2 UIAA information sheet. The use of acetazolamide at altitude.

(UIAA information sheets available from: Mountain Medicine Data Centre, St Bartholomew's Hospital, 38 Little Britain, London EC1.) 